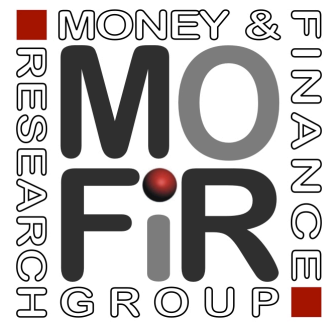

\title{
STEADY STREAMS AND SUDDEN BURSTS: PERSISTENCE PATTERNS IN REMITTANCE DECISIONS
}

\author{
Giulia Bettin Riccardo Lucchetti
}

Working paper no. 97

July 2014 


\title{
Steady streams and sudden bursts: persistence patterns in remittance decisions
}

\author{
Giulia Bettin* Riccardo Lucchetti ${ }^{\dagger}$
}

\begin{abstract}
This paper is the first systematic attempt to investigate the factors affecting time persistence in remittance behaviour at the individual level. We argue that the time profile of remittance flows from individual migrants is of considerable theoretical relevance and also has very important policy implications.

By using micro-level data from the German Socio-Economic Panel (SOEP) we apply a wide variety of discrete choice (static and dynamic) panel models and show that persistence occurs at the individual level due to observable characteristics (individual income, household characteristics, etc.) but also to time-invariant unobserved individual characteristics. In addition, remittance decisions seem to be significantly influenced by "true state dependence", namely correlation between past actual behaviour and future propensity to remit.
\end{abstract}

JEL codes: F22, F24, C23, C25

Keywords: Migration, Remittances, Persistence, Discrete panel data models, State dependence

\section{Introduction}

Academic research on remittance behaviour of migrants has developed enormously in the last years, chiefly due to the increasing importance these transfers have in improving living conditions and promoting development in low-income countries.

Motivations to remit have been thoroughly analysed in several theoretical and empirical contributions, as Rapoport and Docquier (2006) describe in detail. Remittances may of course derive from altruistic feelings for those left

\footnotetext{
*Dipartimento di Scienze Economiche e Sociali and Money and Finance Research Group (Mo.Fi.R.), Università Politecnica delle Marche - P.le Martelli 8, 60121 Ancona (Italy) Tel. +39071 2207079 - g.bettin@univpm.it.

${ }^{\dagger}$ Dipartimento di Scienze Economiche e Sociali and Money and Finance Research Group (Mo.Fi.R.), Università Politecnica delle Marche - P.le Martelli 8, 60121 Ancona (Italy) Tel. +39071 2207092 - r.lucchetti@univpm.it.
} 
behind (Becker, 1974) and thus increase in case of negative income shocks (Funkhouser, 1995; Aggarwal and Horowitz, 2002; Yang and Choi, 2007; Yang, 2008). Besides altruism, however, there are other reasons which could explain migrants' remitting behaviour (Lucas and Stark, 1985), ranging from exchange motives (Bernheim, Shleifer, and Summers, 1985; Cox, 1987), to inheritance motives (Hoddinott, 1994; de la Briere, Sadoulet, de Janvry, and Lambert, 2002), insurance contracts (Lucas and Stark, 1985; Rosenzweig, 1988) and loan repayments (Cox, Eser, and Jimenez, 1998; Poirine, 1997).

Altough remittances have become one of the main sources of external finance in many developing countries, their persistence over time has received surprisingly little attention so far in the literature. According to the latest World Bank figures ${ }^{1}$, remittances account for $48 \%$ of GDP in Tajikistan, $31 \%$ in Kyrgyzstan, 25\% in Lesotho, Moldova and Nepal. Given their size, the way in which remittance flows vary over time is a crucial factor for the future of the migrants' countries of origin. Policy evaluation of measures that might affect remittances in the short term (e.g. changes in transfer costs) needs to take into account how they could eventually translate into long lasting effects due to the persistence of remittances over time.

During the recent global financial crisis, aggregate remittances have proved to be extremely "resilient" compared to other international financial flows such as FDI and private loans (Ratha and Sirkeci, 2010; Sirkeci, Cohen, and Ratha, 2012), as clearly shown in Figure $1^{2}$. Investigating the micro-level factors this time persistence can be traced back to is hence a particularly important research question.

In principle, persistence in total remittance flows may depend on individual migrants sending money home constantly and regularly over time, or may simply be the effect of aggregation. In order to formulate realistic scenarios on the future trends in remittance flows from developed to developing countries, it is therefore necessary to investigate the micro determinants of the intertemporal decision to remit: for example, if transfers rapidly decrease after migrants have moved abroad, continued migration becomes a prerequisite for keeping remittance inflows constant over time. If, alternatively, individuals keep or stop sending remittances in response to a given condition, changes in such condition may affect aggregate flows abruptly and dramatically.

Despite an increasing interest on the dynamics of remittance volumes (Czaika and Spray, 2014), the way migrants plan their remittance strategy through time has not yet been comprehensively investigated in the literature, since most empirical and theoretical models have been forced to consider the decision to remit money to the home country in a static framework due to

\footnotetext{
${ }^{1}$ World Bank Migration and Remittances Factbook 2011, http://goo.gl/DjdHFp.

${ }^{2}$ The standard deviation of remittance series between 1990 and 2011 was 0.06 , much lower than that of FDI (0.19) and not even comparable to the standard deviation of private loans (0.89).
} 
Figure 1: Private capital flows to developing countries, 1990-2011 Source: World Bank Migration and Remittances Factbook 2011.

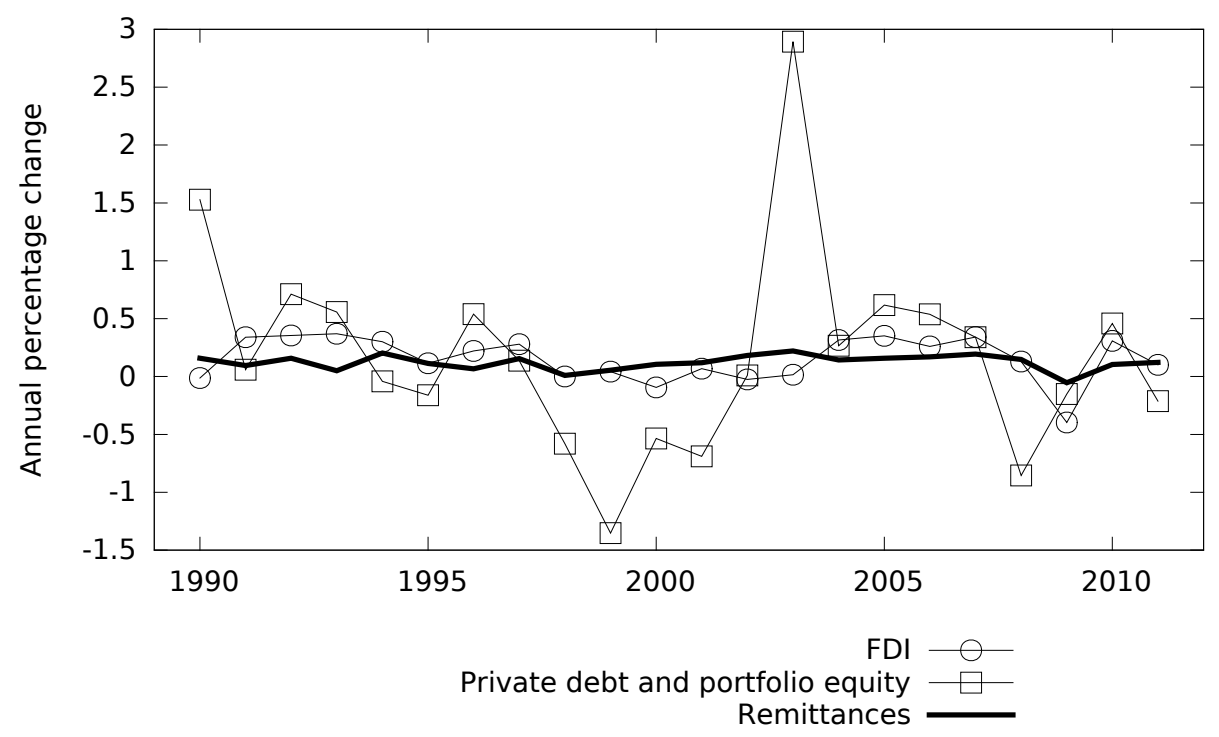

the lack of longitudinal data.

The aim of this paper is to develop an empirical model that fully accounts for the intertemporal nature of individual remittance decisions. Such nature might depend on the persistence in observable characteristics that influence the choice to remit in each period - immigrants' characteristics and characteristics of the recipients in the home country - but also on an intrinsically forward-looking strategy. In addition, the evolution of remitting decisions over time is likely to be influenced by the degree of altruism (Becker, 1974), that can be considered as part of each individual's timeinvariant psychological attitude.

By means of both static and dynamic panel models, we look at the main determinants of the probability to remit ${ }^{3}$ and the sources of persistence of remittance behaviour. As we will argue later in the paper, the issue of "true state dependence" is particularly relevant and needs to be dealt with by using appropriate statistical methods (Heckman, 1981).

The empirical model is built on data from the German Socio-Economic Panel (SOEP). Among European immigration countries, Germany is the source of relevant remittance outflows that have been equal on average to $0.5 \%$ of its GDP in the last decades compared to $0.2 \%$ in the UK, $0.4 \%$ in France and $0.3 \%$ in Italy. If we look at the importance of remittances

\footnotetext{
${ }^{3}$ In this paper we will not use data on the amounts remitted because this would have made the empirical setup far too complex to fit in one paper. We, however, are determined to deal with this aspect in future research.
} 
Figure 2: Remittances from Germany to selected destination countries, 2010-2012

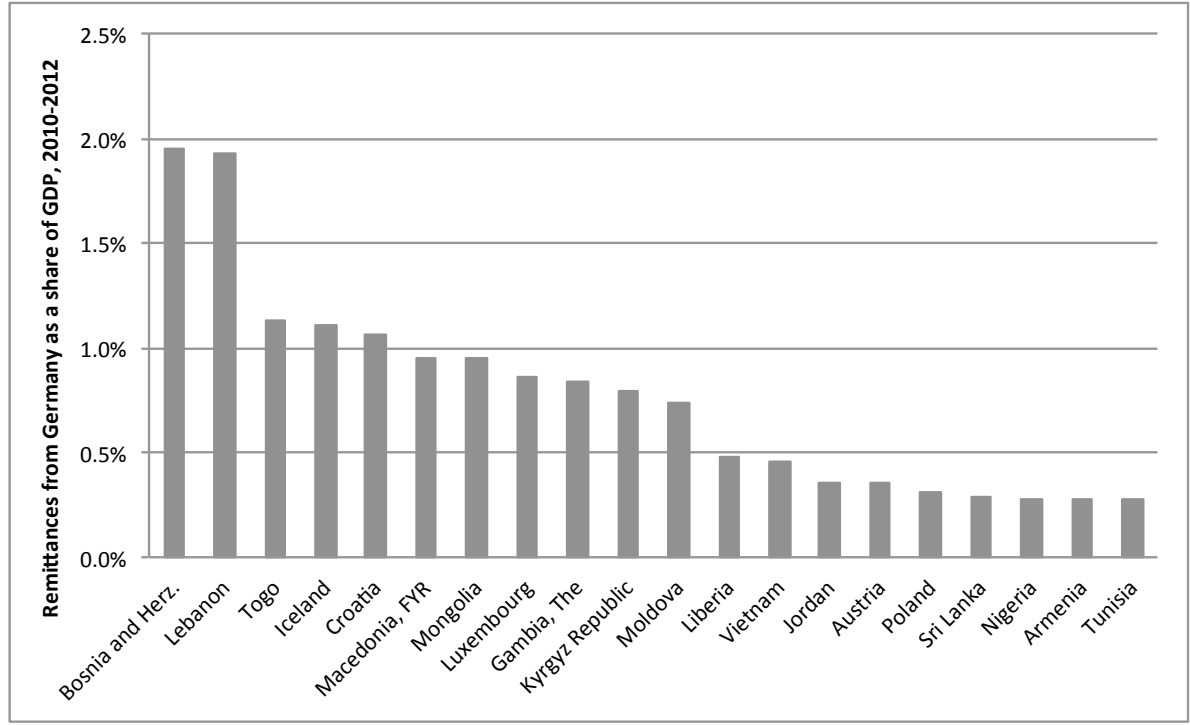

from Germany for the receiving economies (Figure 2), it is rather clear that these transfers are a source of external finance of considerable importance for several small countries. In addition, this dataset represents a unique asset for our analysis compared to standard remittance studies in the literature because of the long time span over which migrant households are observed (Funkhouser, 2012).

The evidence we provide shows that the actual remitting behaviour of migrants through time is extremely complex, as most remitters seem to follow highly irregular time patterns that are not easy to reconcile with existing theoretical models of remittance behaviour, nor with their principal empirical counterparts. However, our results unambiguously reveal that persistence of remittance behaviour happens at the individual level, and that persistence in macro-level data is not simply a by-product of aggregation. Moreover, there is strong evidence in favour of "true state dependence", that can be interpreted as an indirect indication of the existence of persistent motives to remit or, alternatively, long-term agreements between senders and receivers.

Section 2 introduces the issue of persistence in remitting behaviour and briefly reviews the empirical literature based on longitudinal data. Section 3 describes the data and offers some preliminary evidence to highlight the importance of persistence in remitting behaviour. The empirical setup of the analysis is discussed in Section 4. Section 5 presents our results, while section 6 concludes. 


\section{The persistence of remitting behaviour}

To our knowledge, a fully intertemporal formal model of remittance behaviour has never been considered in the literature. The "standard" setup starts with the following maximisation problem:

$$
\operatorname{Max} U_{i}(C, R)
$$

under a common budget constraint, where $C$ is consumption, $R$ are remittances and $U_{i}(\cdot)$ is the utility function for a certain individual $i$. The general model above can be analysed under various respects. The possible co-existence of "selfish" and "altruistic" motives for remitting and all the attempts that have been made in the literature to discriminate between different motivations to remit ${ }^{4}$ can be easily formalised through equation (1). Building on the same framework, the idea that the utility derived from remittances $\left(\frac{\partial U_{i}(\cdot)}{\partial R}\right)$ may be zero in certain individuals has been used to explain the fact that in empirical studies non-sending migrants could represent a large share of the sample (Cox, Eser, and Jimenez, 1998; Sinning, 2011; Bettin, Lucchetti, and Zazzaro, 2012).

However, considering a rational, forward-looking agent and given that remittances may be used as a form of saving, a more appropriate model would be

$$
\operatorname{Max} \int_{0}^{\infty} e^{-r t} U_{i}\left(C_{t}, R_{t}\right) \mathrm{d} t
$$

under a suitable intertemporal budget constraint. ${ }^{5}$ To the extent that remittances represent an alternative to consumption, the standard arguments in favour of forward-looking behaviour apply: the flow of remittances should be smooth over time as per the individual's expectations on future income. Conversely, events which alter income expectations (for example, the unexpected loss of a job) should affect remittance decisions as well as consumption plans. Note that, from an observational point of view, it may be hard to distinguish the effect of remittance smoothing from individual heterogeneity. In both cases, the observable outcome would be stability of actions across time.

In addition, preferences vary across migrants and over time: in other words, the marginal rate of substitution $\frac{\partial U_{i}(\cdot) / \partial C_{t}}{\partial U_{i}(\cdot) / \partial R_{t}}$ between consumption and remittances may be not only heterogenous across individuals, but also nonconstant over time. Hence, structural non-remitters (that is, individual

\footnotetext{
${ }^{4}$ See Rapoport and Docquier (2006) and Carling (2008) for comprehensive theoretical and empirical surveys on this issue.

${ }^{5}$ In general, remittances could also be present in the budget constraint in so far as they are meant to finance some kind of asset accumulation. However, considering this additional channel would add nothing to the discussion that follows and we omit this point for the sake of conciseness.
} 
for whom $\left.\frac{\partial U_{i}(\cdot)}{\partial R_{t}}=0\right)$ follow a constant behaviour by definition, while migrants for whom remittance is a possibility may remit or not as a direct consequence of a budget constraint. Consequently, the more stable their income is, the more regular their behaviour through time should be.

Changes in socio-economic factors may also translate into changes in the individual utility function according to which migrants start or stop remitting. The most obvious example in this regard are common events affecting household composition, such as a marriage or the birth of a child. The length of migrants' absence (Czaika and Spray, 2014), the intention to return to the country of origin and the way such intention may change over time are also very likely to affect the intertemporal nature of remittance behaviour, as Poirine (1997) pointed out.

Detailed evidence on remitting behaviour based on longitudinal data is still scarce in the literature. A few contributions rely on longitudinal data on receiving households. Duval and Wolff (2010) investigate the determinants of remittances using the Living Standard Measurement Surveys (LSMS) in Albania from 2002 to 2004 but the longitudinal nature of their data set is not exploited in a significant manner. The LSMS longitudinal data have also been employed in Dimova and Wolff (2009) and Duval and Wolff (2012) to investigate the role of remittances in triggering chain migration from Bosnia and Herzegovina and influencing financial expectations in Albania, respectively. Finally, Funkhouser (2006) applies the difference-in-difference approach to LSMS data for Nicaragua to look at the impact of migration and remittances on labour market outcomes and poverty level of receiving households.

The determinants of remittances have also been investigated on the basis of longitudinal surveys of migrants in the host country. Dustmann and Mestres (2010) use German Socio-Economic Panel (SOEP) data and investigate how return plans affect remittances. Their work is currently the only one that fully exploits the panel dimension in the dataset via dynamic GMM estimates, although they do not discuss the issue of persistence in remitting behaviour and focus on other aspects instead.

\section{Data and descriptive evidence}

The empirical analysis presented here is based on data from the German Socio-Economic Panel (SOEP) for the period between 1997 and $2012^{6}$. This dataset is a representative longitudinal survey carried out since 1984 by

\footnotetext{
${ }^{6}$ The data used in this paper was extracted using the Add-On package PanelWhiz for Stata. PanelWhiz (http://www.PanelWhiz.eu) was written by Dr. John P. HaiskenDeNew. See Haisken-DeNew and Hahn (2010) for details. The PanelWhiz generated Stata script to retrieve the data used here is available from us upon request. Any data or computational errors in this paper are our own.
} 
yearly interviewing a large sample of households residing in Germany. Individual questionnaires are administered together with household-level ones so that for every person in the sample information concerning demographic and socioeconomic individual characteristics are matched with details on household composition and budget decisions. Immigrant households were included in the sample from the very beginning of the study in 1984 but the nationality groups initially covered were only those with the longer tradition of immigration to Germany: Turks, Italians, Greeks, Spaniards and Yugoslavians $^{7}$. Only from 1995 onwards the immigrant subsample was significantly increased to include also other nationalities. The list of origin countries $^{8}$ covered is reported in the Appendix.

Unfortunately, the major shortcoming affecting SOEP subsample of migrants is the lack of detailed information on socio-economic conditions of potential receivers in the home country. Available information simply concerns the family structure (who the relatives abroad are). Missing data on the family of origin are probably the reason why, despite its wide usage in the literature on migrants' assimilation and performance in the labour market $^{9}$, SOEP has not yet been employed in many contributions to analyse remittance behaviour over time ${ }^{10}$.

Among the few existing works based on SOEP data, Holst, Schäfer, and Schrooten $(2008,2010,2011)$ investigate the relationship between gender, transnational networks, legal status and the remittance patterns while Bollard, McKenzie, Morten, and Rapoport (2011) include SOEP data in their cross-country study and shed light on how remittance patterns change according to migrants' different educational levels. Piracha and Zhu (2007) and Bauer and Sinning (2011) compare savings rate of immigrants in Germany (both temporary and permanent) with those of the native-born population while Sinning (2011) focuses on the differences in remitting behaviour between permanent and temporary migrants. As mentioned before, Dustmann and Mestres (2010) look at the way return plans affect remittances by focussing on the period 1984-1995, when only the five major nationality groups in Germany were surveyed.

In our analysis, we restrict the sample to the adult immigrant population. Immigrants are defined as foreign-born individuals who immigrated to

\footnotetext{
${ }^{7}$ Formal guest workers programmes were implemented in West Germany during the 1950 s and 1960s. Foreign workers were recruited from Southern Europe first (bilateral agreements with Italy and Greece were signed in 1955 and 1960, respectively), but soon from Turkey and former Yugoslavia as well.

${ }^{8}$ Immigrants who entered the SOEP in the 1980s indicated Yugoslavia as their home country. Aggregate data have been calculated as mean values for the group of current countries that were once enclosed in the Federal Republic.

${ }^{9}$ See Schmidt (1997), Dustmann and Soest (2002), Constant and Massey (2003), Zibrowius (2011) and Facchini, Patacchini, and Steinhardt (2014) among the others.

${ }^{10} \mathrm{~A}$ discussion on the way we deal with this drawback in our analysis is presented in Section 4 .
} 
Germany since 1948, as per the SOEP criterion. Such definition includes individuals who became German citizens after immigration while it excludes second-generation immigrants (see also Bauer and Sinning (2011)). We are forced to exclude all waves before 1996 due to the inconsistency in the questions on remittance behaviour before and after that date, which might also explain why in 1996 the share of remitters was much lower than all subsequent years (see the bottom row of Table 1). All these problems led us to consider the 1997-2012 period in our empirical analysis; the robustness of our results, however, has been checked also by including 1996 in the sample ${ }^{11}$.

When looking at preliminary descriptive statistics on remitting migrants by country of origin (Table 1), it is rather clear that marked differences exist across nationalities. If on average the share of migrants which send money back is around $10 \%$ in the total sample with a slightly diminishing trend over time, migrants from Ex-Yugoslavia and from Asian and Pacific countries show a markedly higher propensity to remit. Among the nationalities with the longest tradition of immigration to Germany, the different figures for Turkey on one hand and Italy, Greece and Spain on the other might reflect the relative level of economic development of these countries.

\subsection{Stylised facts on remittances' time patterns}

Classifying migrants as "remitters" or "non-remitters" is harder than it seems at first sight, because it is difficult to define a status on the basis of an instantaneous action which may occur at irregular intervals. Empirical studies which rely on cross-sectional data usually exploit the information provided by surveys about interviewees having remitted at least once in the reference period (last year, in most cases).

When analysing panel data, the behaviour is observed for a certain time span. A first element to be taken into account is the fact that the decision to remit seems persistent over time; in addition, the distinction between remitters and non-remitters across time might vary substantially according to the sample unit one chooses to consider, namely individuals or households. At the household level, remittance patterns are likely to be more complicated than at the individual level: a couple of migrant adults, for example, could decide to send money alternatively to the husband's and the wife's family of origin. In this way, the observed persistence in remittance behaviour would be higher at the household level compared to what we would observe by considering each migrant on her/his own.

The following descriptive analysis is therefore carried out by alternatively considering individuals and households as sample units, in order to verify potential differences and to assess how they eventually would need to be taken into account when estimating the empirical model.

\footnotetext{
${ }^{11}$ Results are available from the authors upon request.
} 


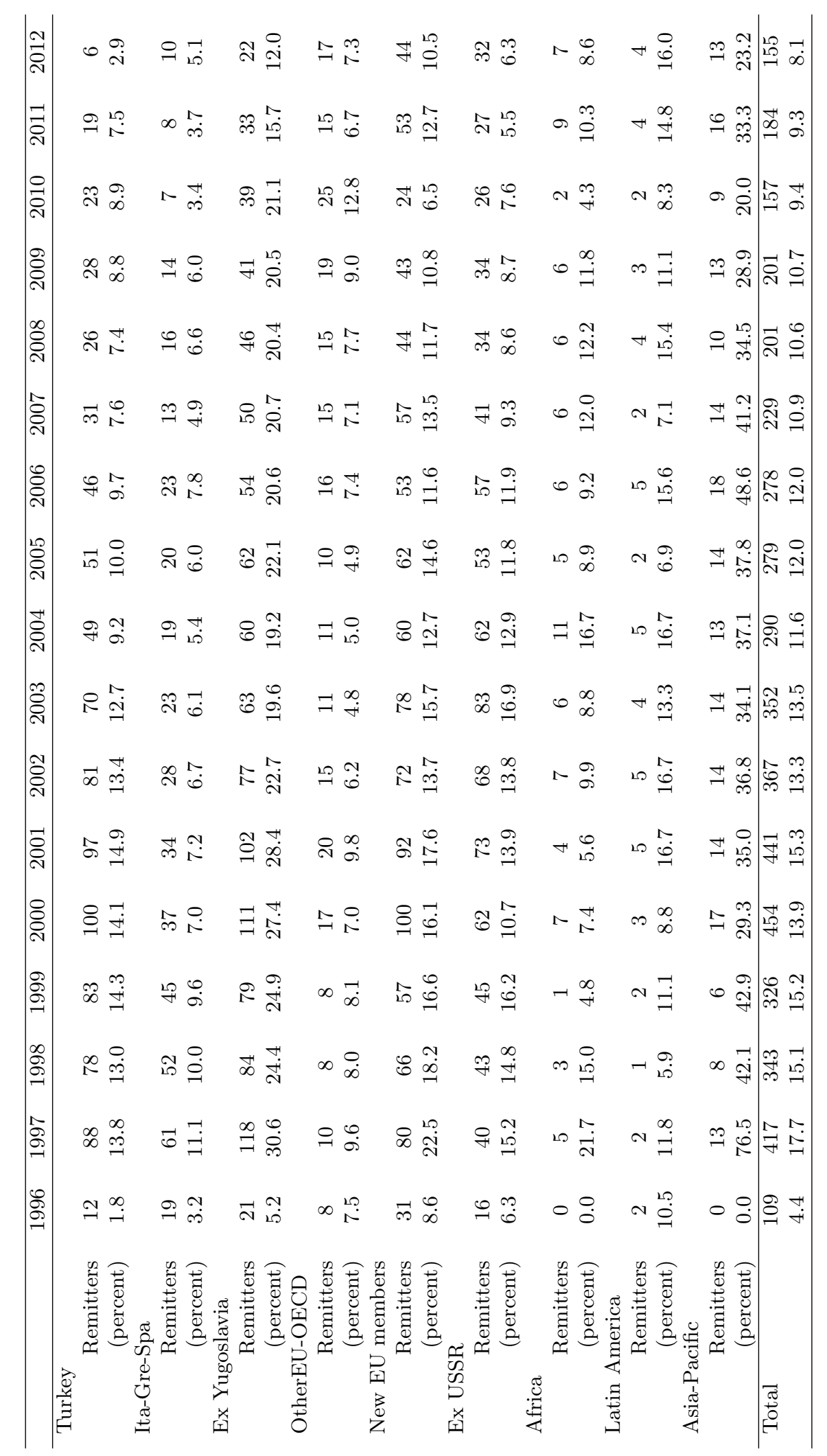


Table 2: Probability to remit

Individuals

\begin{tabular}{lccc}
\multicolumn{4}{c}{$y_{t}$} \\
$y_{t-1}$ & 0 & 1 & Total \\
\hline 0 & 27659 & 2001 & 29660 \\
& 93.3 & 6.7 & 100 \\
1 & 1800 & 2333 & 4133 \\
& 43.6 & 56.4 & 100 \\
\hline Total & 29459 & 4334 & 33793 \\
& 87.2 & 12.8 & 100
\end{tabular}

Households

\begin{tabular}{lccc}
\multicolumn{4}{c}{$y_{t}$} \\
$y_{t-1}$ & 0 & 1 & Total \\
\hline 0 & 16348 & 1415 & 17763 \\
& 92.0 & 8.0 & 100 \\
1 & 1300 & 2081 & 3381 \\
& 38.5 & 61.5 & 100 \\
\hline Total & 17648 & 3496 & 21144 \\
& 83.5 & 16.5 & 100
\end{tabular}

Note: $y_{t}=1$ indicates that remittances were sent at time $t$.

Table 2 shows a cross-tabulation of the probability to remit in time $t$ and $t-1$ for individuals and households, respectively. Frequencies are higher on the diagonals: $93 \%$ of individuals and $92 \%$ of households who had not remitted at $t-1$ did the same at $t$, while $56 \%$ of individuals who remit at time $t-1$ still do so at time $t$. As we would expect, persistence is slightly higher once we take household-level remittances into account, with $61 \%$ of households still remitting at time $t$ after having remitted at time $t-1$.

As can be easily seen, the most frequently observed pattern in Table 2 is $0 / 0$, that is individuals (or households) who do not send remittances either at time $t-1$ nor at time $t$. If, however, we focus to units who were observed to send remittances at least once, the situation is less clear: Table 3 presents an indicator of "irregularity over time", that is the number of actual state transitions over potential ones, which is computed for each individual (household) who appears more than once by applying the following formula:

$$
F_{i}=\frac{\sum_{i=2}^{T_{i}}\left|y_{i, t}-y_{i, t-1}\right|}{T_{i}-1},
$$

where $y_{i, t}$ is a dummy variable indicating whether individual (household) $i$ has remitted money in year $t$ and $T_{i}$ stands for the number of years an individual (household) has been interviewed in SOEP. If a migrant decided in each period whether to remit or not by flipping a fair coin, $F_{i}$ should be around 0.5. As can be seen, some people (households) never change their status, but those who do may do so several times, and a sizeable proportion even exceeds the 0.5 threshold. In other words, for most migrants who have remitted money at least once, starting and stopping are not rare events.

It should be evident that classifying migrants into stable remitters and non-remitters is rather difficult. All the different observed patterns are not easy to reconcile with existing theoretical models of remittance decisions, nor with their principal empirical counterparts, that as a rule do not investigate 
Table 3: Transitions between remitter and non-remitter status as a share of the presence in SOEP

\begin{tabular}{lcccc}
\hline$F_{i}$ & $\begin{array}{c}\text { Frequency of } \\
\text { individuals }\end{array}$ & $\%$ & $\begin{array}{c}\text { Frequency of } \\
\text { households }\end{array}$ & $\%$ \\
\hline$F_{i}=0$ & 98 & 6.51 & 89 & 7.95 \\
$0<F_{i} \leq 0.1$ & 82 & 5.44 & 59 & 5.27 \\
$0.1<F_{i} \leq 0.2$ & 319 & 21.18 & 208 & 18.59 \\
$0.2<F_{i} \leq 0.3$ & 256 & 17.00 & 203 & 18.14 \\
$0.3<F_{i} \leq 0.4$ & 244 & 16.20 & 180 & 16.09 \\
$0.4<F_{i} \leq 0.5$ & 211 & 14.01 & 157 & 14.03 \\
$0.5<F_{i} \leq 0.6$ & 63 & 4.18 & 36 & 3.22 \\
$0.6<F_{i} \leq 0.7$ & 50 & 3.32 & 41 & 3.66 \\
$0.7<F_{i} \leq 0.8$ & 20 & 1.33 & 15 & 1.34 \\
$0.8<F_{i} \leq 0.9$ & 5 & 0.33 & 2 & 0.18 \\
$0.9<F_{i} \leq 1$ & 158 & 10.49 & 129 & 11.53 \\
\hline Total & 1506 & 100 & 1119 & 100 \\
\hline
\end{tabular}

Note: excluding individuals/households who never remitted

the evolution of the phenomenon over time. However, one thing we can be confident of, on the basis of the evidence gathered here, is that the persistence of remittance strategies is observed both at the household and at the individual level, and that its features are broadly similar.

In the rest of the article, our preferred empirical strategy is therefore to take individuals as sampling units. First, using household-level data would not provide more significant insights on the time pattern of remittances than the individual level. Second, this choice is motivated by the fact that many variables traditionally regarded as determinants of remittance decisions in the empirical literature are by definition individual-level variables (gender, age, education, return intention and so forth) and their aggregation at the household level would be rather arbitrary. ${ }^{12}$

\section{Empirical strategy}

The descriptive statistics presented in the previous section should make it clear that building a statistical model for the remittance behaviour of individuals through time must make appropriate provision for its persistence.

\footnotetext{
${ }^{12}$ In order to verify the robustness of our findings we estimated models comparable to those presented later in Section 5 also at the household level, by making specific assumptions on individual-level characteristics. Results are very similar, in terms of size, signs and significance level and are available upon request.
} 
The first element to take into account is that a great deal of observed persistence is due to the fact that the majority of migrants never send money back to their country of origin (see Table 1), according to individual preference heterogeneity previously discussed in Section 2.

The second element is related to the intertemporal nature of remitting behaviour (see Table 2), even though a large share of those who remit seem to do so in an irregular manner (see Table 3), thus suggesting that the decisions to remit or not in a given year is the outcome of a process in which multiple overlapping, and possibly conflicting factors, come into play: the persistence in characteristics of the migrant (for example, individual and household income, employment status etc.); the persistence in characteristics of the recipient; forward-looking behaviour by the migrant, and therefore the allocation of remittances over time at pre-planned intervals; and finally, individual, time-invariant psychological characteristics (for example, the degree of altruism).

\subsection{Choice under static and dynamic behaviour}

If time was irrelevant and migrants made their choices statically in each year, a possible empirical specification to be estimated would be:

$$
y_{i, t}^{*}=\mathbf{x}_{i, t}^{\prime} \beta+\alpha_{i}+\varepsilon_{i, t}
$$

where the binary dependent variable $y_{i, t}=\mathbf{I}\left(y_{i, t}^{*}>0\right)$ indicates whether a given individual $i$ has remitted in year $t$ and $y_{i, t}^{*}$ is the customary latent propensity variable. The vector $\mathbf{x}_{i, t}$ contains a set of observable characteristics of the individual and the households they belong to, ${ }^{13}$ while $\alpha_{i}$ is an individual effect that summarises all unobservable time-invariant characteristics.

From an empirical point of view, a data-generating process as in equation (3) would give rise to persistence in the observed remitting behaviour even in the case of static choices, since persistence through time could simply be a side effect of persistence of the magnitudes on the right-hand side of equation (3). The individual effect $\alpha_{i}$ is clearly persistent by definition, but most of the covariates $\mathbf{x}_{i, t}$ would arguably be persistent too. Moreover, one must also account for the possibility of additional persistent unobserved factors coming into play under the form of autocorrelation of $\varepsilon_{i, t}$.

Hence, evidence of intertemporal behaviour (or lack thereof) cannot emerge from model (3) only; in order to allow for intertemporal behaviour and provide a framework to test for this hypothesis the following extension of equation (3) is needed:

$$
\begin{aligned}
y_{i, t}^{*} & =\varphi y_{i, t-1}+\mathbf{x}_{i, t}^{\prime} \beta+\alpha_{i}+\varepsilon_{i, t} \\
\varepsilon_{i, t} & =\rho \varepsilon_{i, t-1}+\eta_{i, t}
\end{aligned}
$$

\footnotetext{
${ }^{13}$ Descriptive statistics for all explanatory variables are reported in Appendix B.
} 
where $\varepsilon_{i, t}$ may be autocorrelated. A fuller description of our empirical model is provided in section A in the Appendix.

This setup generalises the simple static model in two directions: first, we allow the error term to be autocorrelated, so to capture additional timepersistent factors that may motivate migrants to remit money to their origin country but remain unobservable. In our case, these would mostly include information on the receiving end, on which we have much less data than on the potential sender in the SOEP database. Second, we allow the propensity to send $y_{i, t}^{*}$ to depend directly on the actual realised behaviour in the previous period; this effect is captured by the parameter $\varphi$. The hypothesis of no intertemporal strategy corresponds to the statistically testable hypothesis $\varphi=0$. In that case, observed persistence in an individual sequence of decision is completely explained by the persistence in motivating factors (observable or not). On the contrary, $\varphi \neq 0$ could be considered evidence of a multi-period allocation of remittances.

The fact that $y_{i, t}^{*}$ depends on $y_{i, t-1}$ rather than $y_{i, t-1}^{*}$ has important consequences on the interpretation of the results, as it gives rise to "true state dependence". The seminal paper in analysing true state dependence is Heckman (1981), but the concept is quite popular in a number of different fields, such as labour economics (see eg Stewart (2007)) or health economics (for one, Heiss (2011)). For example, state dependence in unemployment means that the chances to find a job that an individual has at time $t$ depend on her actual state at $t-1$. In our case, the variable determining the propensity to remit at time $t$ is not the lagged propensity itself, but rather the actual decision that the individual took at time $t-1$.

Estimation of equation (3) poses no problems, since the random-effects probit model is nowadays completely standard. On the other hand, its dynamic counterpart deserves a more detailed description. Since equation (4) contains $y_{i, t-1}$ among the explanatory variables, it might resemble an autoregressive model, but several qualifications have to be made, for which we defer again to section $\mathrm{A}$ in the Appendix.

\subsection{The explanatory variables}

The set of explanatory variables $\mathbf{x}_{i, t}$ can be split in several components. A first set, that we call $p_{i, t}$, contains personal characteristics usually considered in the literature as observable determinants of the propensity by an individual to be a remitter: gender ( 1 if male), age, migrant household composition (total number of household members and number of children), time since migration (expressed in decades) and its square, intention to stay in Germany (1 for staying, 0 for going back to the home country), German citizenship (1 if acquired), migrants' individual yearly labour income and household net yearly income (both in natural logarithm), migrant's employment status (1 if employed). In order to accommodate possible nonlinear effects of age, 
we also include a dummy variable (young) equal to 1 if the individual was under $24 .{ }^{14}$ The educational level of the migrant $e_{i, t}$, expressed by the number of years of education and its square, is also included here; apart from being an important descriptor of the individual, this variable may motivate remittances directly, since education might have been funded by the family back home and call for debt repayment (Lucas and Stark, 1985).

A second set of explanatory variables is used to proxy for the factors that can be traced back to the origin household in the home country and could induce the migrants to send remittances. In turn, these include country-level variables, ${ }^{15}$ which we call $Y_{j(i), t}$, and information on the family members who live in the country of origin $\left(h_{i, t}\right)$.

The use of macro variables in micro-level analyses on remittances is not new in the literature (Bettin, Lucchetti, and Zazzaro, 2012; AmuedoDorantes and Pozo, 2013). Since we cannot control for the income level of relatives abroad, we use the ratio between per capita $\mathrm{GDP}^{16}$ in the home country $^{17}$ and Germany (in logs) to proxy for the living conditions of those left behind. GDP differential between home and host country might indeed act as a main driver of remittance flows at the aggregate level (Frankel, 2011). Its square is also added to control for possible nonlinear effects. In addition, we also include a set of "pseudo-country" dummies in which we use the same country groups as in Table 1, to control for time-invariant factors, such as distance, which might exert an influence on the strength of the relationship with the family at home and therefore affect remittance behaviour. As for the structure of the receiving household, we include four dummy variables respectively for the presence of parents, children, partner and siblings in the home country. We assume that these variables can be split in two subgroups: mostly working-age $h_{i, t}^{w}$ (which includes partner and siblings) and mostly non-working-age $h_{i, t}^{w}$ (parents and children).

In this way, we can partially control for persistence in receiving households' characteristics even if microdata on the economic situation of the family at home are missing.

\footnotetext{
${ }^{14}$ This was found to be empirically preferable to the common choice of including age squared both in terms of model fit and numerical stability.

${ }^{15} \mathrm{We}$ adopt the convention of indicating with $j(i)$ the country from which individual $i$ comes from.

${ }^{16} \mathrm{GDP}$ per capita is expressed in constant 2005 international dollars. Data are drawn from World Development Indicators database. We also tried the inclusion of other macro time-varying variables, such as growth rates and GDP volatility (Amuedo-Dorantes and Pozo, 2013), but they were never significant in any specification and were eventually dropped.

${ }^{17}$ During the interview, the home country was not chosen from a predefined list, but rather declared freely. For this reason, a non negligible share of individuals list as their home country a territorial entity that is not recognized as a sovereign state per se or no longer exists as such. As a consequence, data for Benelux are calculated as means between those for Belgium and the Netherlands. For Kurdistan and Ex-Yugoslavia we make use of data for Iraq and Serbia, respectively.
} 
Table 4: Effects of selected factors on the propensity to remit

\begin{tabular}{r|cccc}
\hline Motivation & $Y_{j(i), t}$ & $h_{i, t}^{n}$ & $h_{i, t}^{w}$ & $e_{i, t}$ \\
\hline Altruistic & - & + & - & $n . d . e$ \\
Non-altruistic & $+/-$ & $n . d . e$ & $+/-$ & + \\
\hline Overall & $?$ & + & $?$ & + \\
\hline
\end{tabular}

Note: ? = ambiguous effect; n.d.e.= no direct effect.

As already recalled in the introduction, motivations to remit can range from pure altruism to absolute self-interest and clear-cut empirical tests on the prevalence of different motives are extremely hard to perform. However, after roughly categorising motivations as "altruistic" or "non-altruistic", the effects of the variables included in $\mathbf{x}_{i, t}$ may be summarised in the matrix shown in Table 4 (Rapoport and Docquier, 2006).

According to Table 4, the effect of $h_{i, t}^{n}$ and $e_{i, t}$ should be positive and would not anyway allow to discriminate between motives that may actually coexist in the same individual. Conversely, the sign of $Y_{j(i), t}$ and $h_{i, t}^{w}$ is uncertain, and depends on the prevalence, in the dataset at hand, of the altruistic vs the non-altruistic motives to remit. A positive sign on both coefficients could be read as prevalence of the non-altruistic motivations, while a negative sign might conceal either purely altruistic feelings or the coexistence of both motives.

\section{$5 \quad$ Estimation results}

\subsection{Static vs. dynamic models: state dependence in the propensity to remit}

Estimation results are reported in Table 5, where we estimate equations (3) and (4) together with a pooled probit model.

A comparison between pooled probit estimates (column [1]) and static RE estimates (column [2]) reveals that the signs and the significance levels of the coefficients are not very different from across models ${ }^{18}$. We interpret the near-constancy of parameters as the individual time-invariant factors $\alpha_{i}$ being substantially orthogonal to observed factors and, hence, representing a distinct source of persistence with respect to observable individual and household-level characteristics. The estimated variance of $\alpha_{i}$ (not reported in the table) in model [2] equals 1.662 and is extremely significant, thus hinting at the fact that individual time-invariant characteristics cannot be disregarded when modelling the probability to remit over time.

\footnotetext{
${ }^{18}$ It should be stressed, however, that the size of the coefficients is not directly comparable across estimation methods (columns).
} 
Table 5: Propensity to remit: probit estimates

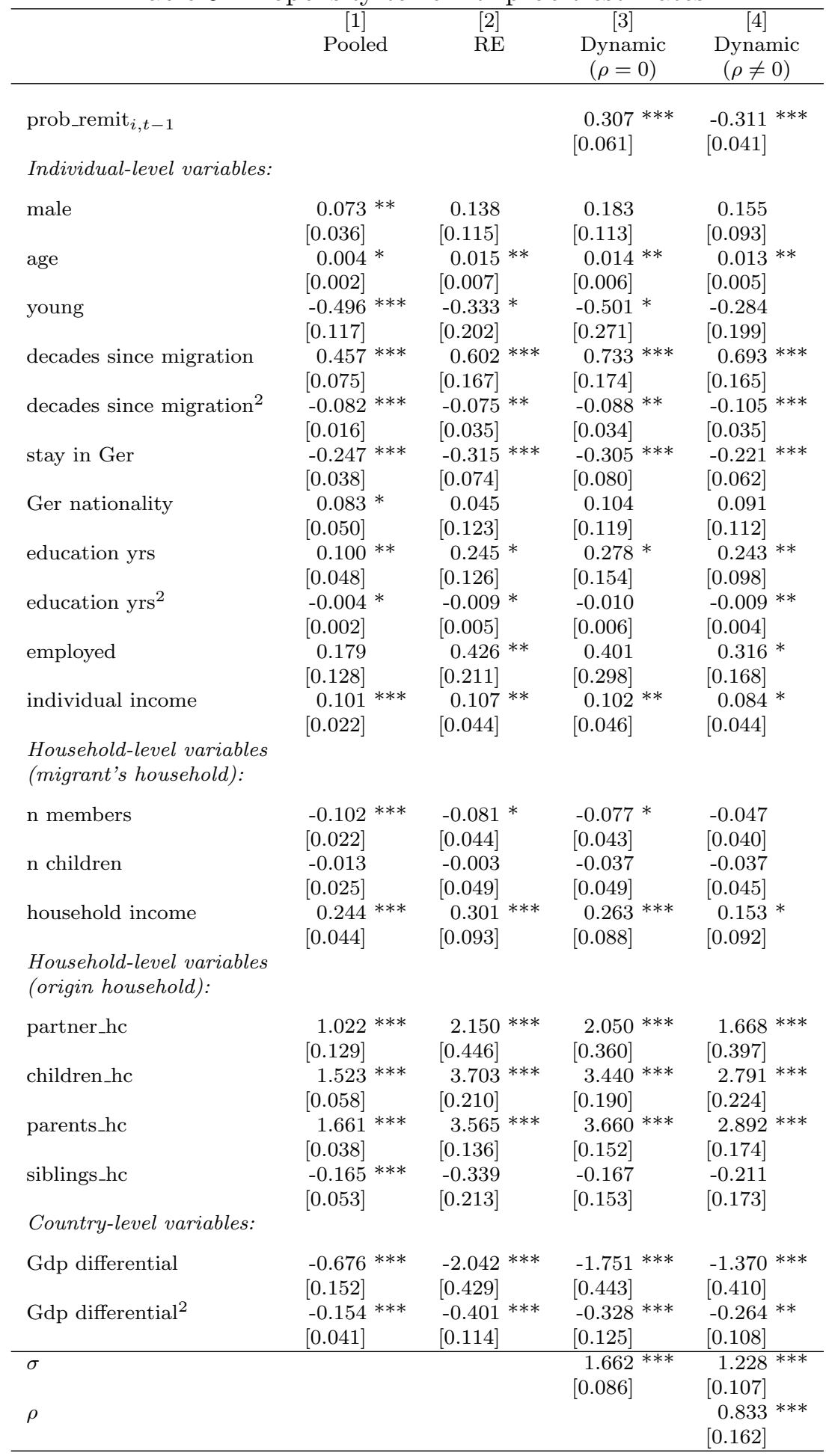

Note: * significant at $10 \%$ level, ** significant at $5 \%$ level, *** significant at $1 \%$ level.

13864 observations across 2345 units. Standard errors in square brackets. Constant, time and country dummies included in all specifications. $\sigma$ is a measure of the magnitude of the individual effect $\alpha_{i}$, relative to that of the disturbance $\varepsilon_{i, t} 16 \rho$ is the first-order autocorrelation of $\varepsilon_{i, t}$. 
When we move from the static to the dynamic model in column [3], the lagged dependent variable is strongly significant with a positive sign, thus suggesting that an additional source of persistence has to be taken into account: the remittance behaviour looks like an intertemporal forwardlooking strategy. As recalled in Section 4.1, however, time continuity in remittance behaviour might also derive from persistence in unobservables, namely in receivers' socio-economic conditions, which we are not able to take into account through our dataset.

Results reported in column [4], where we allow for autocorrelation of $\varepsilon_{i, t}$, show that indeed persistence in unobserved factors significantly affects remittances: the parameter $\rho$ (the first-order autocorrelation of $\varepsilon_{i, t}$ ) is positive and equal to 0.871 meaning that what we cannot observe today at time $t$ is highly dependent from what we were not able to observe at time $t-1$. After controlling for persistence in the unobservables, true state dependence is still highly significant, but with a negative sign. To the extent that $\rho$ is able to capture potential near-constancy in origin households' conditions over time, the propensity to remit negatively depends on what the migrant actually did the year before. The remitting strategy seems fully intertemporal and, at least in the SOEP data, based on a multi-year plan.

A possible, interesting interpretation of $\varphi$ being negative once persistence in unobservables is controlled for is that individuals may decide to concentrate remittance sending in as few occasions as possible, perhaps in response to sizeable fixed transaction costs. Transaction costs have been shown to influence significantly remitters' decisions in other empirical studies, such as Bettin, Lucchetti, and Zazzaro (2012).

\subsection{The determinants of remittance decisions}

The signs and the significance levels of most coefficients are coherent across all specifications and broadly in line with the findings from previous literature. The effects of the main drivers of remittance behaviour, therefore, seem remarkably robust even when taking persistence into account.

As for individual-level variables, differences emerge in the probability to remit between male and female migrants, the former being more likely to remit (Carling, 2008). The effect of age on the propensity to remit is increasing: migrants under 24 exhibit a much lower propensity, while after that age the effect is much milder. ${ }^{19}$

The probability to remit decreases with the intention to stay perma-

\footnotetext{
${ }^{19}$ By employing SOEP data for 1984-1995, Dustmann and Mestres (2010) and Sinning (2011) also find a positive effect of the age of the migrant on the probability to remit, but they do not control for a nonlinear impact. Menjivar, Da Vanzo, Greenwell, and Valdez (1998), in contrast, find an inverted U-shape relationship between the age of the immigrant and the amount remitted in the main equation and a U-shape relationship in the selection equation.
} 
nently in Germany. Along the same line, in their GMM estimates Dustmann and Mestres (2010) find that the probability to remit is 16 percentage points higher and the total amount transferred $1.3 \mathrm{log}$ points larger for individuals with temporary migration plans. While holding German citizenship hardly plays any role in affecting remittance decision, time since migration has a non linear, U-shaped impact on the propensity to remit, as found in many other contributions (Lucas and Stark, 1985; de la Briere, Sadoulet, de Janvry, and Lambert, 2002; Liu and Reilly, 2004).

Unsurprisingly, migrant's individual income is a key factor for the probability to remit, thus highlighting the importance of economic conditions in the host country in determining remittance patterns over time. When looking at income effects on the propensity to remit, however, we should mention the possibility of our results being biased by endogeneity problems which, unfortunately, we are not able to take properly into account at this stage of analysis $^{20}$. Differently from other empirical results (Amuedo-Dorantes and Pozo, 2013), employment status here seems not to affect the propensity to remit in any estimated specification.

As predicted by the repayment hypothesis (see Bollard, McKenzie, Morten, and Rapoport, 2011), the educational level of migrants positively affects their probability to remit: educated migrants may have to pay back the investment in their education made by the family of origin. Such an effect, however, is non linear in the migrant's years of education, the squared term displaying a negative and significant coefficient across all specifications. Dustmann and Mestres (2010) instead show that, in the 1984-1995 period, the probability to remit is negatively affected by the number of years of education.

Results concerning the characteristics of migrants' households in Germany are also quite robust across specifications. The probability to remit is positively affected by household income and negatively affected by household size. The number of children in the household, instead, never plays any significant role.

As far as the origin household in the home country is considered, the presence of either parents, partners or children abroad always exert a strong, positive effect, while having siblings in the home country reduces the probability to remit. Such a negative effect might stem from the fact that altruistic motives are less urgent as to siblings compared to parents, wives and children. Alternatively, migrants who belong to larger families might have a

\footnotetext{
${ }^{20}$ It should be noted, however, that possible endogeneity of income is likely to be a major issue in a remittance equation (amount) but probably represents a minor issue in the decision whether to remit or not (Bettin, Lucchetti, and Zazzaro, 2012). In addition, endogeneity would only prevent us from reading the estimated coefficients as behavioural parameters, but would not hinder our main purpose here, which is the study of persistence in remittance decisions and the factors which affect it. We therefore leave this issue for future work.
} 
lower incentive to remit if they know there are siblings at home who look after their parents ${ }^{21}$. The effect, however, is significant only in the pooled specification.

As expected, the GDP differential between the home country and Germany exerts a negative effect on the probability to remit, with a significant element of concavity: as the economic distance between home and host country decreases, migrants become less likely to send money.

If we consider the predictions deriving from different motivations to remit summarized in Table 4, the positive effect of the presence of non-working age household members ( $i$. e., children and parents) in the home country cannot help us discriminating between altruistic and non-altruistic motives. At the same time, however, we find some support in favour of altruistic motivations deriving from the negative coefficient associated to the GDP differential between Germany and the home country.

\subsection{Robustness analysis}

In order to assess the robustness of our result with respect to the statistical assumptions on the individual effect $\alpha_{i}$ in the RE probit model, we also estimate a few logit models.

To evaluate the impact of possibly neglecting state dependence, we first ran two static models (a pooled and a fixed-effects logit model), in which the $\varphi$ parameter was set to zero. The one most comparable to our preferred specification is the the dynamic logit panel model by Bartolucci and Nigro (2010). This model can be written as

$$
y_{i, t}^{*}=\varphi y_{i, t-1}+\mathbf{x}_{i, t}^{\prime} \beta+\mathbf{w}_{i, t}^{\prime} \gamma+e_{t}^{*}\left(\alpha_{i}, \mathbf{x}_{i}, \mathbf{w}_{i}\right)+\alpha_{i}+\varepsilon_{i, t}
$$

In this case, estimation is carried out via conditional maximum likelihood by treating the individual effects $\alpha_{i}$ as fixed rather than random.

In this sense, this estimator can be considered as a dynamic extension of the familiar conditional fixed-effect logit estimator for panel data introduced by Rasch (1960) and made popular by Chamberlain (1984). ${ }^{22}$ The customary remarks when comparing fixed- and random-effects estimators also apply here: FE estimators annihilate the individual effects completely rather than modelling it, so possible issues with their distribution and/or

\footnotetext{
${ }^{21}$ Such a result would not be in contrast with inheritance-related motives to remit either. As de la Briere, Sadoulet, de Janvry, and Lambert (2002) point out, the effect of the number of potential heirs (siblings, in our case) is a priori ambiguous. On the one hand, sharing parent's assets with siblings decreases the return to investment in remittances; on the other hand, competition among heirs can increase the parent's response to their child's transfers and thus stimulate more remittances. Our estimation results seem to support the prevalence of the first effect (sharing effect) on the second one (competition effect).

${ }^{22}$ Compared to other extensions that have been proposed in the literature, such as the one by Honoré and Kyriazidou (2000), Bartolucci and Nigro's estimator offers several practical advantages. See, again, Bartolucci and Nigro (2010).
} 
Table 6: Propensity to remit: logit estimates

\begin{tabular}{|c|c|c|c|}
\hline & $\begin{array}{c}{[1]} \\
\text { Pooled }\end{array}$ & $\begin{array}{c}{[2]} \\
\text { Fixed eff. }\end{array}$ & $\begin{array}{c}{[3]} \\
\text { Dynamic FE }\end{array}$ \\
\hline prob_remit $_{t-1}$ & & & $\begin{array}{l}0.830 * * * \\
{[0.081]}\end{array}$ \\
\hline \multicolumn{4}{|l|}{ Individual-level variables: } \\
\hline educ_yrs & $\begin{array}{r}0.123 \\
{[0.086]}\end{array}$ & $\begin{array}{r}0.013 \\
{[0.225]}\end{array}$ & $\begin{array}{r}0.054 \\
{[0.241]}\end{array}$ \\
\hline educ_yrs $^{2}$ & $\begin{array}{l}-0.005 \\
{[0.004]}\end{array}$ & $\begin{array}{r}0.003 \\
{[0.010]}\end{array}$ & $\begin{array}{r}0.001 \\
{[0.011]}\end{array}$ \\
\hline decades since migration & $\begin{array}{l}0.825 * * * \\
{[0.137]}\end{array}$ & & \\
\hline decades since migration ${ }^{2}$ & $\begin{array}{l}-0.143 * * * \\
{[0.030]}\end{array}$ & $\begin{array}{r}0.050 \\
{[0.054]}\end{array}$ & $\begin{array}{l}0.132 \\
{[0.062]}\end{array}$ \\
\hline stay in Ger & $\begin{array}{l}-0.440 * * * \\
{[0.068]}\end{array}$ & $\begin{array}{l}-0.159 \\
{[0.101]}\end{array}$ & $\begin{array}{r}-0.171 \\
{[0.116]}\end{array}$ \\
\hline Ger nationality & $\begin{array}{r}0.099 \\
{[0.091]}\end{array}$ & $\begin{array}{r}0.360 \\
{[0.190]}\end{array}$ & $\begin{array}{r}0.241 \\
{[0.196]}\end{array}$ \\
\hline employed & $\begin{array}{r}0.274 \\
{[0.245]}\end{array}$ & $\begin{array}{l}0.947 * * * \\
{[0.292]}\end{array}$ & $\begin{array}{l}1.113 * * * \\
{[0.402]}\end{array}$ \\
\hline individual income & $\begin{array}{l}0.193 * * * \\
{[0.041]}\end{array}$ & $\begin{array}{l}0.201 \\
{[0.067]}\end{array}$ & $\begin{array}{r}0.221 \\
{[0.075]}\end{array}$ \\
\hline $\begin{array}{l}\text { Household-level variables } \\
\text { (migrant's household): }\end{array}$ & & & \\
\hline $\mathrm{n}$ members & $\begin{array}{l}-0.194 * * * \\
{[0.041]}\end{array}$ & $\begin{array}{l}-0.057 \\
{[0.064]}\end{array}$ & $\begin{array}{l}-0.045 \\
{[0.068]}\end{array}$ \\
\hline n children & $\begin{array}{l}-0.023 \\
{[0.047]}\end{array}$ & $\begin{array}{r}0.010 \\
{[0.069]}\end{array}$ & $\begin{array}{r}0.085 \\
{[0.074]}\end{array}$ \\
\hline household income & $\begin{array}{r}0.451 * * * \\
{[0.081]}\end{array}$ & $\begin{array}{c}0.277 \\
{[0.145]}\end{array}$ & $\begin{array}{r}0.182 \\
{[0.165]}\end{array}$ \\
\hline $\begin{array}{l}\text { Household-level variables } \\
\text { (origin household): }\end{array}$ & & & \\
\hline partner_hc & $\begin{array}{l}1.831 * * * \\
{[0.236]}\end{array}$ & & \\
\hline children_hc & $\begin{array}{l}2.721 * * * \\
{[0.105]}\end{array}$ & & \\
\hline parents_hc & $\begin{array}{l}3.019 * * * \\
{[0.072]}\end{array}$ & & \\
\hline siblings_hc & $\begin{array}{l}-0.355 * * * \\
{[0.093]}\end{array}$ & & \\
\hline Country-level variables: & & & \\
\hline Gdp differential & $\begin{array}{l}-1.109 * * * \\
{[0.269]}\end{array}$ & $\begin{array}{l}-2.530 * * \\
{[1.037]}\end{array}$ & $\begin{array}{l}-2.407 * * \\
{[1.108]}\end{array}$ \\
\hline Gdp differential $^{2}$ & $\begin{array}{l}-0.242 * * * \\
{[0.074]}\end{array}$ & $\begin{array}{l}-0.693 * * \\
{[0.305]}\end{array}$ & $\begin{array}{l}-0.565 * \\
{[0.326]}\end{array}$ \\
\hline $\mathrm{N}$ obs & 13864 & 6761 & 5535 \\
\hline $\mathrm{N}$ units & 2345 & 846 & 700 \\
\hline
\end{tabular}

Note: ${ }^{*}$ significant at $10 \%$ level, ${ }^{* *}$ significant at $5 \%$ level, ${ }^{* * *}$ significant at $1 \%$ level. Standard errors in square brackets. Constant, time and country dummies included in all specifications, where possible (see text). 
exogeneity are eliminated; this comes at the cost of a substantial reduction of the available information, both in being unable to use time-invariant explanatory variables ${ }^{23}$ and in the reduction in the sample size. The latter aspect is, unfortunately, particularly relevant in our case: as is well known, the FE logit estimator cannot use data for those individuals for which $y_{i, t}$ is constant across time. Given the high proportion of non-remitters (see Table 1 ), the issue is particularly severe, so the loss of precision becomes sizeable.

Since $\varepsilon_{i, t}$ is assumed to be logistic, rather than normal as in equation (4), the coefficients in the two models are not comparable between equations in magnitude, but only in sign; furthermore, equation 6 contains the additional term $e_{t}^{*}(\cdot)$, which can be interpreted as the possible influence on $y_{i, t}^{*}$ of the expected utility from future choices (see Bartolucci and Nigro (2010), section 3.2 for details). Consequently, while a direct comparison between the two models (4) and (6) is impossible, we consider this estimation technique extremely valuable in order to compare qualitatively the results either in terms of persistence characteristics of the remittance behaviour and in terms of the robustness of the effects by the variables $\mathbf{x}_{i, t}$ and $\mathbf{w}_{i, t}$.

Unfortunately, Bartolucci and Nigro's estimator is not available for autocorrelated disturbances, so we cannot use it as a robustness check for column 4 in Table 5.

Results are reported in Table 6: despite the many differences between the probit and logit estimators and the different nature of the treatment of individual effects (RE vs FE), we found that all the exogenous factors which proved to be significant in our prefered specification keep their sign and concavity unchanged in the set of logit estimates, the only difference being lack of significance for a few of them; this is unsurprising, considering how much smaller the usable sample is for fixed-effects estimators. Morover, the dynamic logit model exhibits features that are very much in line with the corresponding probit estimate, including sizeable time persistence in remittance behaviour. So, on the whole, we are confident that our baseline results, as shown in Table 5, are very robust to a whole range of possible statistical problems.

\section{What have we learned? Conclusions and direc- tions for future research}

In this paper, we develop an empirical model for the propensity to remit which takes into full account the evolution of the phenomenon over time. To the best of our knowledge, the dynamic nature of remittance decisions which we addressed here has never been given a comprehensive treatment in the literature despite being of paramount importance from a developing

\footnotetext{
${ }^{23}$ This also applies to the "time since migration" variable, which becomes collinear with age.
} 
country's perspective in order to design strategies to maintain remittance inflows stable over time.

Our empirical analysis based on SOEP data on immigrants residing in Germany unambigously shows that there is much insight to be gained by moving from a static description of a migrant's remittance behaviour to a dynamic one. The first notable result we obtain is that persistence in remittance behaviour does occur at the individual level; therefore, the resilient behaviour we observe at the macroeconomic level is not simply a result which derives from aggregation of individual remittance choices. Countries relying on remittances inflow for macroeconomic stability should hence be extremely careful in monitoring the factors behind the choices of their diaspora abroad, as changes in exogenous conditions may have the potential for altering remittance flows in abrupt and unexpected ways.

As for the question on what these conditions are, we find that, despite being a possibly irregular phenomenon for a sizeable portion of migrants, persistence through time of individual remittance choices can be traced back to several factors. Even after controlling for observable characteristics which exert a strong influence on remittances and are known to have a persistent time profile, such as individual income, employment status, relative income between host and home countries, we find that time-invariant unobserved individual characteristics - as proxied by the individual effect in the panel regression - are also an important factor of persistence. Our interpretation of this result is that individual heterogeneity is the outcome of two separate overlapping effects: actual heterogeneity in individual preferences and remittance smoothing across time.

From the methodological viewpoint, what we consider our most important result is that dynamic empirical models which take both state dependence and autocorrelation in unobservables into account can mitigate the bias deriving from missing information on migrants and origin households. This is an important aspect for future empirical research on remittance behaviour, due to the extreme difficulties in getting senders-receivers matched dataset.

Of course, persistence might be observed not only in the propensity to remit, but also in the amount of money sent home. Structural models for the amount remitted which take selection bias into proper account (Bettin, Lucchetti, and Zazzaro, 2012; Brown, Leeves, and Prayaga, 2014) should hence be generalised to accomodate persistence of individual behaviour through time $^{24}$. This empirical task is left as object of future research; it nevertheless represents a crucial element from a policy perspective in order to assess the real effects remittances - and hence emigration - might have for the

\footnotetext{
${ }^{24}$ Methods for estimating dynamic models subject to endogenous sample selection in a panel data context have been proposed by Kyriazidou (2001), Gayle and Viauroux (2007) and more recently by Semykina and Wooldridge (2011). None, however, seem to be readily applicable to remittances.
} 
future of developing countries.

\section{References}

Aggarwal, R., And A. W. Horowitz (2002): "Are International Remittances Altruism or Insurance? Evidence from Guyana Using MultipleMigrant Households," World Development, 30(11), 2033-2044.

Amuedo-Dorantes, C., and S. Pozo (2013): "Remittances and Portfolio Values: An Inquiry using Immigrants from Africa, Europe, and the Americas," World Development, 41(C), 83-95.

Bartolucci, F., and V. Nigro (2010): “A Dynamic Model for Binary Panel Data With Unobserved Heterogeneity Admitting a $\sqrt{n}$-Consistent Conditional Estimator," Econometrica, 78(2), 719-733.

Bauer, T., And M. Sinning (2011): "The savings behavior of temporary and permanent migrants in Germany," Journal of Population Economics, $24(2), 421-449$.

Becker, G. S. (1974): "A Theory of Social Interactions," Journal of Political Economy, 82(6), 1063-93.

Bernheim, B. D., A. Shleifer, and L. H. Summers (1985): "The Strategic Bequest Motive," Journal of Political Economy, 93(6), 1045-76.

Bettin, G., R. Lucchetti, and A. Zazzaro (2012): "Endogeneity and sample selection in a model for remittances," Journal of Development Economics, 99, 370-384.

Bollard, A., D. McKenzie, M. Morten, and H. Rapoport (2011): "Remittances and the Brain Drain Revisited: The Microdata Show That More Educated Migrants Remit More," World Bank Economic Review, $25(1), 132-156$.

Brown, R. P., G. Leeves, and P. Prayaga (2014): "Sharing Norm Pressures and Community Remittances: Evidence from a Natural Disaster in the Pacific Islands," Journal of Development Studies, forthcoming.

Carling, J. (2008): "The Determinants of Migrant Remittances," Oxford Review of Economic Policy, 24(3), 581-598.

Chamberlain, G. (1984): "Panel data," in Handbook of Econometrics, ed. by Z. Griliches, and M. D. Intriligator, vol. 2, chap. 22, pp. 1247-1318. Elsevier. 
Constant, A., And D. S. Massey (2003): "Self-selection, earnings, and out-migration: A longitudinal study of immigrants to Germany," Journal of Population Economics, 16(4), 631-653.

Cox, D. (1987): "Motives for Private Income Transfers," Journal of Political Economy, 95(3), 508-46.

Cox, D., Z. Eser, And E. Jimenez (1998): "Motives for private transfers over the life cycle: an analytical framework and evidence for Peru," Journal of Development Economics, 55(1), 57-80.

Czaika, M., and J. Spray (2014): "Drivers and Dynamics of Internal and International Remittances," Journal of Development Studies, forthcoming.

de la Briere, B., E. Sadoulet, A. de Janvry, and S. Lambert (2002): "The roles of destination, gender, and household composition in explaining remittances: an analysis for the Dominican Sierra," Journal of Development Economics, 68, 309-328.

Dimova, R., and F.-C. Wolff (2009): "Remittances and Chain Migration: Longitudinal Evidence from Bosnia and Herzegovina," IZA Discussion Papers 4083, Institute for the Study of Labor (IZA).

Dustmann, C., and J. Mestres (2010): "Remittances and temporary migration," Journal of Development Economics, 92(1), 62-70.

Dustmann, C., And A. V. Soest (2002): "Language and the earnings of immigrants," Industrial and Labor Relations Review, 55(3), 473-492.

Duval, L., AND F.-C. WolfF (2010): "Remittances matter: longitudinal evidence from Albania," Post-Communist Economies, 22(1), 73-97.

Duval, L., And F.-C. WolfF (2012): "Longitudinal evidence on financial expectations in Albania: Do remittances matter?," Economics of Transition, 20(1), 137-161.

Facchini, G., E. Patacchini, and M. Steinhardt (2014): "Migration, Friendship Ties and Cultural Assimilation," IZA Discussion Papers 7881, Institute for the Study of Labor (IZA).

Frankel, J. (2011): "Are Bilateral Remittances Countercyclical?," Open Economies Review, 22(1), 1-16.

Funkhouser, E. (1995): "Remittances from International Migration: a Comparison of El Salvador and Nicaragua," The Review of Economics and Statistics, 77(1), 137-146. 
(2006): "The effect of emigration on the labor market outcomes of the sender household: a longitudinal approach using data from Nicaragua," Well-Being and Social Policy, 2(2), 5-25.

(2012): "Using Longitudinal Data to Study Migration and Remittances," in Handbook of Research Methods in Migration, ed. by C. Vargas Silva. Edward Elgar Publishing, Inc.

Gayle, G.-L., and C. Viauroux (2007): "Root-N consistent semiparametric estimators of a dynamic panel-sample-selection model," Journal of Econometrics, 141(1), 179-212.

Geweke, J. (1989): "Bayesian Inference in Econometric Models Using Monte Carlo Integration," Econometrica, 57(6), 1317-39.

Haisken-DeNew, J. P., And M. H. Hahn (2010): "PanelWhiz: Efficient Data Extraction of Complex Panel Data Sets - An Example Using the German SOEP," Journal of Applied Social Science Studies, 130(4), 643654 .

Hajivassiliou, V. A., and D. L. McFadden (1998): "The Method of Simulated Scores for the Estimation of LDV Models," Econometrica, 66(4), 863-896.

Heckman, J. J. (1981): "Heterogeneity and State Dependence," in Studies in Labor Markets, NBER Chapters, pp. 91-140. University of Chicago Press.

Heiss, F. (2011): "Dynamics of self-rated health and selective mortality," Empirical Economics, 40(1), 119-140.

Hoddinote, J. (1994): "A Model of Migration and Remittances Applied to Western Kenya," Oxford Economic Papers, 46, 459-476.

Holst, E., A. Schäfer, And M. Schrooten (2008): "Gender, Migration, Remittances: Evidence from Germany," Discussion Papers of DIW Berlin 800, DIW Berlin, German Institute for Economic Research.

(2010): "Gender, Transnational Networks and Remittances: Evidence from Germany," Discussion Papers of DIW Berlin 1005, DIW Berlin, German Institute for Economic Research.

(2011): "Remittances and Gender: Theoretical Considerations and Empirical Evidence," IZA Discussion Papers 5472, Institute for the Study of Labor (IZA).

Honoré, B. E., and E. Kyriazidou (2000): "Panel Data Discrete Choice Models with Lagged Dependent Variables," Econometrica, 68(4), 839-74. 
Hyslop, D. R. (1999): "State Dependence, Serial Correlation and Heterogeneity in Intertemporal Labor Force Participation of Married Women," Econometrica, 67(6), 1255-1294.

Keane, M. P. (1994): "A Computationally Practical Simulation Estimator for Panel Data," Econometrica, 62(1), 95-116.

Keane, M. P., and R. M. Sauer (2009): "Classification Error in Dynamic Discrete Choice Models: Implications for Female Labor Supply Behavior," Econometrica, 77(3), 975-991.

Kyriazidou, E. (2001): "Estimation of Dynamic Panel Data Sample Selection Models," Review of Economic Studies, 68(3), 543-72.

LiU, Q., AND B. ReILly (2004): "Income transfers of Chinese rural migrants: some empirical evidence from Jinan," Applied Economics, 36(12), $1295-1313$.

Lucas, R. E., and O. Stark (1985): "Motivations to remit: evidence from Botswana," Journal of Political Economy, 93(5), 901-918.

Menjivar, C., J. Da Vanzo, L. Greenwell, and R. B. Valdez (1998): "Remittance behaviour among Salvadoran and Filippino immigrants in Los Angeles," International Migration Review, 32(1), 97-126.

MirandA, A. (2007): "Dynamic probit models for panel data: A comparison of three methods of estimation," United Kingdom Stata Users' Group Meetings 2007 11, Stata Users Group.

Piracha, M., And Y. Zhu (2007): "Precautionary Savings by Natives and Immigrants in Germany," SOEPpapers 33, DIW Berlin, The German Socio-Economic Panel (SOEP).

PoIRINe, B. (1997): "A Theory of Remittances as an Implicit Family Loan Arrangement," World Development, 25(4), 589-611.

Rapoport, H., and F. Docquier (2006): "The Economics of Migrants' Remittances," in Handbook on the Economics of Giving, Altruism and Reciprocity, ed. by S. Kolm, and J. Mercier Ythier, vol. 2, pp. 1135-1198. Elsevier.

RAsch, G. (1960): "Probabilistic Models for Some Intelligence and Attainment Tests," Denmark Paedogiska.

Ratha, D., AND I. SiRkeci (2010): "Remittances and the global financial crisis," Migration Letters, 7(2), 125-131. 
Rosenzweig, M. R. (1988): "Risk, Implicit Contracts and the Family in Rural Areas of Low-income Countries," Economic Journal, 98(393), 1148-70.

SchmidT, C. M. (1997): "Immigrant performance in Germany: Labor earnings of ethnic German migrants and foreign guest-workers," The Quarterly Review of Economics and Finance, 37(Supplement), 379-397.

Semykina, A., And J. M. Wooldridge (2011): "Estimation Of Dynamic Panel Data Models With Sample Selection," Journal of Applied Econometrics.

Sinning, M. (2011): "Determinants of Savings and Remittances: empirical Evidence from Immigrants to Germany," Review of Economics of the Household, 9(1), 45-67.

Sirkeci, I., J. H. Cohen, And D. Ratha (eds.) (2012): Migration and Remittances during the Global Financial Crisis and Beyond. The World Bank.

Stewart, M. B. (2007): "The interrelated dynamics of unemployment and low-wage employment," Journal of Applied Econometrics, 22(3), 511-531.

Wooldridge, J. M. (2005): "Simple solutions to the initial conditions problem in dynamic, nonlinear panel data models with unobserved heterogeneity," Journal of Applied Econometrics, 20(1), 39-54.

YANG, D. (2008): "Coping with disaster: the Impact of hurricanes on international financial flows, 1970-2002," The B.E. Journal of Economic Analysis \& Policy, 8(1 (Advances)), Article 13.

YANG, D., AND H. Chol (2007): "Are remittances insurance? Evidence from rainfall shocks in the Philippines," The World Bank Economic Review, 21(2), 219-248.

Zibrowius, M. (2011): "Convergence or divergence? Immigrant wage assimilation patterns in Germany," IWQW Discussion Paper Series 03/2011, Friedrich-Alexander-Universität Erlangen-Nürnberg, Institut für Wirtschaftspolitik und Quantitative Wirtschaftsforschung (IWQW). 


\section{Appendices}

\section{A The empirical model}

The empirical setup we adopt for estimating our dynamic panel probit model is essentially the same as in Keane and Sauer (2009); we summarise here its main features.

The main equation of interest is a probit model of the kind

$$
\begin{aligned}
y_{i, t}^{*} & =\varphi y_{i, t-1}+\mathbf{x}_{i, t}^{\prime} \beta+\alpha_{i}+\varepsilon_{i, t} \\
\varepsilon_{i, t} & =\rho \varepsilon_{i, t-1}+\eta_{i, t}
\end{aligned}
$$

where $|\rho|<1$ and $\eta_{i, t}$ is a white-noise sequence, independent of $\alpha_{i}$ and of all the explanatory variables, The observable vector $\mathbf{x}_{i, t}$ contains a set of strictly exogenous conditioning random variables; $\alpha_{i}$ is an individual effect, summarising all unobservable time-invariant characteristics, which is assumed to be a zero-mean normal random variable independent of $\mathbf{x}_{i, t}$ and $\varepsilon_{i, t}$ for all $t$. The time index $t$ ranges from 1 to $T_{i}$, where $T_{i}$ may vary across individuals.

Apart from the need for non-trivial numerical optimisation techniques to compute the estimates (as opposed to what happens in linear models), consistent estimation requires the specification of an auxiliary model for the initial observation $y_{i, 0}$. This is known in the literature as the "initial conditions problem", first elucidated by Heckman (1981), who suggested to use for the purpose an approximation to the true undconditional distribution of $y_{i, 0}$. Equations (7)-(8) are therefore supplemented by an initial condition equation

$$
y_{i, 0}^{*}=\mathbf{z}_{i}^{\prime} \pi+\theta \alpha_{i}+u_{i} .
$$

The set of explanatory variables $\left(\mathbf{z}_{i}^{\prime}\right)$ for equation (9) need not coincide with those for the main equation $\left(\mathbf{x}_{i}^{\prime}\right)$, so that in principle $u_{i}$ and $\varepsilon_{i, 0}$ are not the same random variable, although they are likely to be strongly correlated; this is why the individual effect $\alpha$ has to be multiplied by a scalar parameter $\theta$, which is likely to lie between 0 and 1 in ordinary circumstances. ${ }^{25}$

Heckman (1981) only considered the case $\rho=0$; the case with autocorrelated disturbances was, instead, analysed by Hyslop (1999). Apart from allowing for autocorrelated disurbances, Hyslop's model departs from Heckman's in two significant respects. First, the numerical techniques it requires

\footnotetext{
${ }^{25}$ The method put forward in Heckman (1981) was based on Gauss-Hermite quadrature methods, which was deemed too complex to implement to be in widespread use for a long time, so the empirical literature has mostly relied on an alternative approach devised by Wooldridge (2005) that is somewhat simpler to implement with standard software. Wooldridge's idea, however, is quite difficult to generalise to autocorrleated disturbances, and we prefer not to use it here. Besides, Miranda (2007) finds Heckman's estimator to have better finite-sample properties by Monte Carlo simulation.
} 
are considerably more complex and CPU-expensive, since the evaluation of the log-likelihood for each unit $i$ calls for the evaluation of $T_{i}$-dimensional integrals of the normal distribution. Moreover, it specifies the auxiliary model (9) by mirroring equation (3), so the regressors of the two equations are the same and $u_{i}$ is the same thing as $\varepsilon_{i, 0}$.

The latter assumption is removed in Keane and Sauer (2009), which we follow, at the cost of introducing an extra parameter, which we call $\tau$, defined as $E\left(u_{i} \cdot \varepsilon_{0,1}\right)$. Since the variance of both these random variables is set to 1 for identification purposes, it follows that $|\tau| \leq 1$ by the Cauchy-Schwartz inequality.

Also, since by repeated substitution

$$
\varepsilon_{i, t}=\rho^{t} \varepsilon_{i, 0}+\sum_{s=1}^{t} \rho^{t-s} \eta_{i, t}
$$

it follows that the covariance matrix of the vector of disturbance terms $\left[u_{i}+\theta \alpha_{i}, \varepsilon_{i, 1}+\alpha_{i}, \ldots, \varepsilon_{i, T_{i}}+\alpha_{i}\right]$ is given by

$$
\Sigma_{i}=\left[\begin{array}{c|cccc}
1+\theta^{2} \sigma_{\alpha}^{2} & \tau \rho+\theta \sigma_{\alpha}^{2} & \tau \rho^{2}+\theta \sigma_{\alpha}^{2} & \tau \rho^{3}+\theta \sigma_{\alpha}^{2} & \ldots \\
\hline \tau \rho+\theta \sigma_{\alpha}^{2} & 1+\sigma_{\alpha}^{2} & \rho+\sigma_{\alpha}^{2} & \rho^{2}+\sigma_{\alpha}^{2} & \cdots \\
\tau \rho^{2}+\theta \sigma_{\alpha}^{2} & \rho+\sigma_{\alpha}^{2} & 1+\sigma_{\alpha}^{2} & \rho+\sigma_{\alpha}^{2} & \cdots \\
\vdots & \vdots & \vdots & \vdots & \ddots
\end{array}\right]
$$

The likelihood for individual $i$ can be therefore written as a definite integral of a $T_{i}$-variate normal random variables with covariance matrix $\Sigma_{i}$; we use for this purpose the GHK algorithm (Geweke, 1989; Hajivassiliou and McFadden, 1998; Keane, 1994) with 256 Halton points for every dimension (we also performed a few experiments with uniform random variates and antithetic uniforms with very little variation on the results). Analytical gradients were used in conjunction with the BFGS algorithm for optimisation.

As for standard errors, we use the "sandwich" estimator $H^{-1}\left(G^{\prime} G\right) H^{-1}$, where $H$ is the Hessian matrix and $G$ is the matrix of scores by individual. 


\section{B Immigrants' countries of origin}

\begin{tabular}{llll}
\hline Afghanistan & Costa Rica & Ireland & Portugal \\
Albania & Croatia & Israel & Romania \\
Algeria & Czech Republic & Italy & Russia \\
Argentina & Denmark & Japan & Singapore \\
Armenia & Egypt & Jordan & Slovakia \\
Australia & El Salvador & Kazakhstan & Slovenia \\
Austria & Eritrea & Korea & South Africa \\
Azerbaijan & Estonia & Kurdistan & Spain \\
Bangladesh & Ethiopia & Kyrgyzstan & Sri Lanka \\
Belarus & Ex-Yugoslavia & Latvia & Sweden \\
Belgium & Finland & Lebanon & Switzerland \\
Benelux & France & Liberia & Tajikistan \\
Bolivia & Georgia & Lithuania & Thailand \\
Bosnia-Herzegovina & Ghana & Luxembourg & Trinidad and Tobago \\
Brazil & Great Britain & Macedonia & Tunisia \\
Bulgaria & Greece & Mexico & Turkey \\
Canada & Holland & Moldavia & Ukraine \\
Chad & Hungary & Namibia & USA \\
Chile & Indonesia & Paraguay & Uzbekistan \\
China & Iran & Philippines & Venezuela \\
Columbia & Iraq & Poland & Vietnam \\
\hline
\end{tabular}

\section{Descriptive statistics}




\begin{tabular}{|c|c|c|c|c|c|c|}
\hline Variable & Mean & SD & $\min$ & $5 \%$ perc. & $95 \%$ perc. & $\max$ \\
\hline remitted & 0.133 & 0.340 & 0 & 0 & 1 & 1 \\
\hline male & 0.474 & 0.499 & 0 & 0 & 1 & 1 \\
\hline age & 42.774 & 12.228 & 16 & 22 & 62 & 64 \\
\hline $\operatorname{age}^{2}$ & 1979.200 & 1045.400 & 256 & 484 & 3844 & 4096 \\
\hline n household & 3.377 & 1.487 & 1 & 1 & 6 & 14 \\
\hline n children & 0.943 & 1.175 & 0 & 0 & 3 & 10 \\
\hline education yrs & 10.886 & 2.525 & 7 & 7 & 15 & 18 \\
\hline education $\mathrm{yrs}^{2}$ & 124.870 & 60.928 & 49 & 49 & 225 & 324 \\
\hline stay in Ger & 0.725 & 0.447 & 0 & 0 & 1 & 1 \\
\hline decades since mig & 2.280 & 1.089 & 0.2 & 0.7 & 4.1 & 6.2 \\
\hline Ger nationality & 0.460 & 0.498 & 0 & 0 & 1 & 1 \\
\hline employed & 0.682 & 0.466 & 0 & 0 & 1 & 1 \\
\hline individual income $(\ln )$ & 9.680 & 1.066 & 2.996 & 7.5692 & 10.961 & 13.052 \\
\hline household income (ln) & 10.276 & 0.565 & 3.689 & 9.2922 & 11.108 & 15.270 \\
\hline partner home & 0.008 & 0.087 & 0 & 0 & 0 & 1 \\
\hline children home & 0.045 & 0.208 & 0 & 0 & 0 & 1 \\
\hline parents home & 0.219 & 0.414 & 0 & 0 & 1 & 1 \\
\hline siblings home & 0.055 & 0.227 & 0 & 0 & 1 & 1 \\
\hline gdp differential (ln) & -0.948 & 0.618 & -4.583 & -1.791 & 0.034 & 0.796 \\
\hline $\operatorname{gdp}$ differential ${ }^{2}(\ln )$ & 1.281 & 1.631 & 0 & 0.007 & 3.209 & 21.009 \\
\hline
\end{tabular}

